\title{
Compare the chick length and weights of the Ross broiler breeder in different ages and farms
}

\author{
Shahabodin Gharahveysi* and Taher Asadi Kenari \\ Department of Animal Science, Qaemshahr Branch, Islamic Azad University, \\ Qaemshahr, Iran \\ Postal Address: Qaemshahr Branch, Islamic Azad University- Tabarsi Road- \\ Qaemshahr-Mazandaran-Iran \\ Postal code: 4849167119
}

\begin{abstract}
$\mathbf{B}^{\mathrm{r}}$ reeder flock age affects the quality and quantity of eggs and chicks. The purpose of this study was to investigate the effect of breeder flock age on egg (quality and quantity) and weight and height of hatched chicks. In recent study 271 fertilizable eggs were selected randomly from 3 farms of broiler breeder. Broiler breeder eggs were used when they were 30 (young), 36 (peak), 43 (after peak), 53 (old), 60 (very old) and 82 (molt) weeks. Collected eggs after hatching were stored during 3 to 4 hours at ambient temperature. Quantitative traits such as weight of chick and chick height were considered. The effect of ages and farms on the chick weight and chick height were significant $(\mathrm{P}<0.001)$. The chick weight increased until 53 weeks then decreased. The chick height increased with age increment. According to limitation of researches about studying the effect of age of broiler breeder flock on the chick production, it is needed to carry out a research to eliminate unknown points. Since the majority of poultry have no sufficient information about the quality of chick and the best age of broiler breeder for buying chicks it could be answered to many questions using the results of this research.
\end{abstract}

Keywords: Age, Breeder, Chick, Height, Weight.

\section{Introduction}

Quality of 1-day chick is related to managing farms of broiler breeder and hatchery factories. Number of salable chicks is very important for manager of hatchery. But for poultry, number of healthy chicks with high growth ability and viable is very vital $[1,2]$. Most of criteria of quality study of 1-day chick are sensitive and unfortunately there is no guideline and reasonable method for this investigation. In the hatchery factories, there is an empirical method for investing on high hatching of flocks. It's seen that after hatching, chicks are clean, dry, fine, without coherence hair and there is no pollution on their bodies, at this time hatching will be successful. Healthy chick must be conscious, cheerful and fresh and respond well to stimulating (such as sound, light etc.) their navel must be completely closed and there was no symptom of wound and swelling. Chick feathers should be completely fine, shining, dry and should not be wet and sticky. Their legs must be yellow and lacking of any curvature or bend. Their Cloak should be healthy, normal and lack of any pollution chicks belly is soft, it should not be curvature, hard and swelled. At joint parts, any inflammation or wound should not be seen. Eyes should be shining; chicks should have weight. Their beak should be considering with each other and have normal shape $[3,4]$. Their paw should be healthy. Any deficiency of genetic should not be seen at chick. Totally, big eggs have no good ability to hatching.

Eggs with weight of 50 to 70 gr are suitable for hatching. Size of egg is effective on the chick traits. Normally, size of chick is $66-68 \%$ of egg size. Thus chicks with eggs that are 60 
gr, averagely have 40 gr weight, however weight of chicks is varied from 34 to 46 gr. Effective factors on chick height include: 1) Managing of broiler breeder flock 2) Age of broiler flock 3) Interval of storage and its condition 4) Condition of incubation. 5) Biological age of chick (time of hatching) [5-8].

Researches have studied the effect of shorttime storage and age of broiler breeder on the hatching, time of hatching, chicks weight, embryo mortality at hatching and chick weight at hatching. Traits were investigated on 2250 hatchable egg from 2 broiler breeder flocks at 1 strain and at ages of 32, 34, 48 and 50 weeks. Eggs were stored for $0,1,2$ days in the eggs storage and were maintained in the covered room. Age of broiler has no effect on the age $(p>0.05)$ [9].

Incubate eggs in the hatching bring out averagely later than stored eggs and (Particularly in comparison with eggs which stored for 1 day) produced (heavy) chicks. Effect of breeder broiler age and interval of storage on the albumen properties and hatchery have been studied in a research [10]. Two tests carried out showed that through them, eggs were collected from 4 flocks of one strain which have same controlling and ration condition. At a temperature of 16 degrees Celsius and $78 \%$ relative humidity they remained, eggs with terms of 1,4 and 8 days remained at storage. Height of albumen and its $\mathrm{PH}$ were recorded before placing at concealed room. At first test, eggs were collected on 32 and 54 weeks and at zero time, 12, 24, 38 and 60 hours of incubation. At second test, eggs were collected on 42 and 59 weeks. At zero day, the PH increased by increasing the flock ages $(\mathrm{P}<0.05)$. The albumen ph of eggs that was stored for 8 days was more than (\%95) fresh eggs. By increasing the age, firstly hatchability increase and then decrease
[10]. The purpose of this study was to investigate the effect of breeder flock age on egg (quality and quantity) and weight and height of hatched chicks.

\section{Material and Methods}

Eggs and chicks

In this study 271 fertilizable eggs were selected randomly from 3 broiler breeder farms. These farms included Dorna Juje Shomal located at Bahmanir town (Northern of Iran), Dorna Juje Delijan located at Delijan city (Northern of Iran) and Zarbal Company of broiler breeder located at Nosrat Abad (Northern of Iran). At the above farms, selected eggs were collected from broilers that were 30 (young), 36 (peak), 43 (after peak), 53 (old), 60 (very old) and 82 weeks (molt, second cycle of production) Table 1). Fertile eggs for hatching were sent to Mehregan hatchery of Amol city (Northern of Iran).

After hatching the eggs, all chickens into cartons for 3 hours at a temperature of 21 to $23^{\circ}$ $\mathrm{C}$ were stored in special warehouses. At this time, the humidity dropped and the chicks were weighed with a digital scale 0.01 accuracy.

Height of chicks using usual ruler were measured and recorded. Chicks in order to measuring their height were laid on the flat surface and then measured from beak to small paw.

Analysis and model

Collected data were manipulated by Excel software (2013). Normal distribution test of data was carried out using SAS (ver. 9.1, 2003) statistical software. Then, initial statistical information (such as descriptive statistic) was calculated. Finally, for trait analysis, LS means procedure of SAS statistical software with a probability level of 0.05 were used. The statistical model was as follows:

TABLE 1. Average production (\%) the broiler breeder farms in different ages (week).

\begin{tabular}{lccc}
\hline Dge & Dorna Juje Shomal & Zorna Juje Delijan & \\
\hline 30 & 75.50 & 73.10 & 72.90 \\
36 & 85.10 & 81.90 & 82.30 \\
43 & 84.00 & 88.40 & 87.50 \\
53 & 75.30 & 77.30 & 67.30 \\
60 & 66.20 & 65.40 & 59.70 \\
82 & 53.70 & 56.90 & 51.20 \\
\hline
\end{tabular}

Egypt. J. Vet. Sci. Vol. 49, No.1 (2018) 
$\mathrm{y}_{\mathrm{ijk}}=\mathrm{m}+\mathrm{H}_{\mathrm{i}}+\mathrm{A}_{\mathrm{j}}+\mathrm{e}_{\mathrm{ijk}}$

Where; $\mathrm{y}_{\mathrm{ij}, \mathrm{k}}$, amount of observation for each trait; $\mathrm{m}$, population mean for each trait; $\mathrm{H}_{\mathrm{i}}$, the effect of the farms; $A_{\text {, }}$, the effect of the broiler breeder age and $\mathrm{e}_{\mathrm{i} \mathrm{k} \mathrm{k}}$, residual effects.

\section{Results and Discussion}

Descriptive statistical of studied traits is presented at Table 2 .

TABLE 2. Descriptive statistical of studied traits .

\begin{tabular}{lccc}
\hline Traits & Number & Mean & Standard Error of mean \\
\hline Chick weight $(\mathrm{gr})$ & 271 & 44.73 & 0.75 \\
Chick height $(\mathrm{cm})$ & 271 & 18.96 & 0.06 \\
\hline
\end{tabular}

TABLE 3. The effect of farms and various ages of broiler breeders on the weight and height of chicks.

\begin{tabular}{lcccc}
\hline & Chick & Weight(gr) & Chick & Height(cm) \\
\hline Farms & Mean & (SE) & Mean & (SE) \\
Dorna Juje Shomal & $42.16^{\mathrm{c}}$ & 0.12 & $18.96^{\mathrm{b}}$ & 0.32 \\
Dorna Juje Delijan & $46.70^{\mathrm{b}}$ & 0.17 & $17.83^{\mathrm{c}}$ & 0.30 \\
Zarbal & $48.95^{\mathrm{a}}$ & 0.23 & $19.74^{\mathrm{a}}$ & 0.26 \\
\hline Age (week) & & & 0.00 \\
30 & $40.01^{\mathrm{e}}$ & 0.04 & $17.65^{\mathrm{e}}$ & 0.00 \\
36 & $41.31^{\mathrm{d}}$ & 0.04 & $19.39^{\mathrm{c}}$ & 0.00 \\
43 & $45.19^{\mathrm{c}}$ & 0.04 & $19.85^{\mathrm{a}}$ & 0.00 \\
53 & $49.16^{\mathrm{a}}$ & 0.05 & $19.68^{\mathrm{b}}$ & 0.01 \\
60 & $48.70^{\mathrm{a}}$ & 0.06 & $19.80^{\mathrm{a}}$ & 0.00 \\
80 & $46.70^{\mathrm{b}}$ & 0.04 & $17.83^{\mathrm{d}}$ & \\
\hline
\end{tabular}

Common letters in each column indicates non-significant difference and uncommon letter in each column indicates presence of significant different at the probable level of 0.05 .

The difference between the weight and height mean of the chicks in the 3 farms is significant ( $P$ $<0.01)$. The chicks hatched from eggs of Zarbal farm had the highest weight and height.

The difference between the height and weight mean of chicks from broilers at the different ages was significant $(\mathrm{P}<0.01)$. In other words, the effect of broiler ages on chick weight and height was significant $(\mathrm{P}<0.01)$.

Just a different between weight mean of the chicks hatched from eggs of broiler chickens aged 53 and 60 weeks was not significant $(\mathrm{P}>0.05)$. Just a different between height mean of broiler
Average weight and height of the chickens tested were $44.73 \mathrm{~g}$ and $18.96 \mathrm{~cm}$ respectively. According to the standard error (SE) of the trait means, it can be seen that the calculation accuracy is high.

The results of the analysis of variance and mean comparisons of traits under study is presented in Table 3. 
Researchers, in a study found young broiler breeder had the lowest weight of eggs [2]. They found that chick height has been increase by increasing age from 27 to 59 weeks [2].

Some researchers found that by increasing age, firstly hatchability increase and then decrease. Lapao et al. and Iqbal et al. showed that by increasing the age, incubation time would be decreased [7, 11]. Also effect of egg weight, breed, age and interference of both, at incubation time, egg weight during transfer and chick weight during hatching were significant $(\mathrm{P}<0.01)$ $[7,10,11]$. Totally, by increasing age of broiler breeder flock, ability of hen and cock to produce suitable egg, hatchability would be decreased.

\section{Conclusion}

Due to the different management conditions in different flocks, the difference between the mean of chick weights and heights was significant. The age of the broiler breeder farms had an additive effect on the weight and height of the chicks (except for the 80 weeks).

\section{Acknowledgements:}

The author appreciates the efforts of all members who participated in this study.

\section{Funding statements}

The authors declare that this work is authors self-funded.

\section{Conflicts of interest:}

The authors declare that there are no conflict of interest.

\section{References}

1. Dibaz, S. Normal egg and abnormality. Hatch technology. Tabriz Publication. Iran. (2000)

2. Hamidu, J.A., Fasenko, G.M., Feddes, J.J.R., O’Dea, E.E., Ouellette, C.A., Wineland, M.J. and Christensen, V.L. The effect of broiler breeder genetic strain and parent flock age on eggshell conductance and embryonic metabolism. Poult. Sci., 86, 2420-2432 (2007).

3. Yassin, H.A., Velthuis, G.J., Boerjan, M., van Riel, J. and Huirne, R.B.M. Field Study on Broiler Eggs Hatchability. Poult. Sci., 87, 2408-2417 (2008).

4. Yahyazadeh, H. Management principle at hatchery unit. Tehran University Publication. Iran (1995).
5. Wilson, H.R. Interrelationships of egg size, chick size, post hatching growth and hatchability. World's Poult. Sci. J., 47, 5-20 (1991).

6. Pedroso, A.A., Andrade, M.A., Cafe, M.B., Leandro, N.S.M., Menten, J.G.M. and Stringhini, J.H. Fertility and hatchability of eggs laid in the pullet-to-breeder transition period and in the initial production period. Anim. Reprod. Sci., 90, 355-364 (2005).

7. Lapao, C., Gama, L.T. and Soares, M.C. Effects of broiler breeder age and length of egg storage on albumen characteristics and hatchability. Poult. Sci., 78, 640-645(1999).

8. Khosravinia, H., Ghasemi, S. and Rafiei Alavi, E. Effect of savory (Satureja khuzistanica) essential oils on performance, liver and kidney functions in broiler chicks. J. Animal Feed Sci., 22 (1), 50-55 (2013).

9. Reis, R.L., Gama, L.T. and Soares, M.C. Effects of Short Storage Conditions and Broiler Breeder Age on Hatchability, Hatching Time, and Chick Weights. Poult. Sci., 76, 1459-1466 (1997).

10. Suarez, M.E., Wilson, H.R., Mather, F.B., Wilcox, C.J. and Mcpherson, B.N. Effect of strain and age of the broiler breeder female on incubation time and chick weight. Poult. Sci., 76, 1029-1036 (1997).

11. Iqbal, J., Hassan Khan, S., Mukhtar, N., Ahmed, T. and Ahmed Pasha, R. Effects of egg size (weight) and age on hatching performance and chick quality of broiler breeder. J. Appl. Anim. Res., 44 (1), 54-64 (2016). 


\section{مقارنة طول ووزن الكتاكيت المنتجة من أمهات سلالة روس مختلفة الاعمار وأماكن المزارع}

شاهابودن غارفيزى ـ طاهر أسادى كنارى - مارى

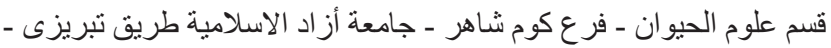

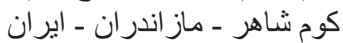

توضح الدراسات ان اختلاف عمر امهات الدواجن يؤثر على كمية ونو عية البيض والكتاكيت المنتجة.

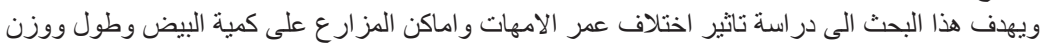

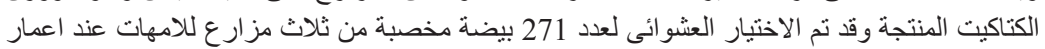

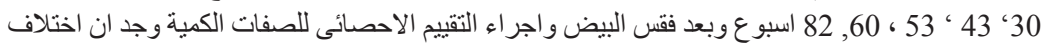

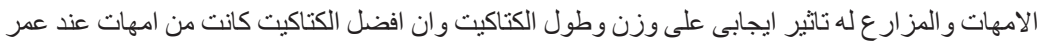

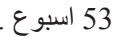

$$
\text { الكلمات الدالة : الكناكيت - عمر الامهات ـ الدواجن }
$$

